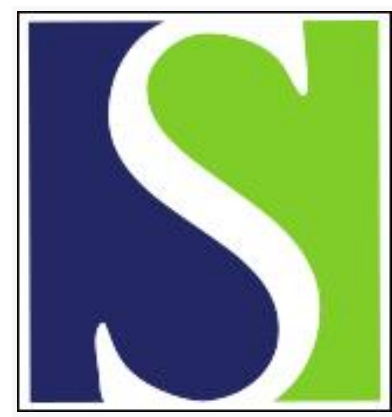

Scand J Work Environ Health 2020;46(4):402-409

https://doi.org/10.5271/sjweh.3881

Published online: 16 Jan 2020, Issue date: 01 Jul 2020

Metabolic syndrome - a risk factor for all-cause disability pension: a prospective study based on the Swedish WOLF cohort

by Lidén E, Karlsson B, Torén K, Andersson E

In this prospective cohort study, Swedish employees with metabolic syndrome had an increased risk for all-cause disability pension, even after adjustment for other risk factors, compared with employees without metabolic syndrome. This implies the need for early recognition and treatment of the metabolic syndrome in order to achieve and maintain work ability throughout the working life.

Affiliation: Department of Occupational and Environmental Medicine, Sahlgrenska Academy, University of Gothenburg, Gothenburg, Sweden. edvard.liden@amm.gu.se

Refers to the following text of the Journal: 2009;35(4):261-281

Key terms: abdominal obesity; blood lipid; disability; disability pension; employee; glucose; hypertension; longitudinal; metabolic syndrome; prospective study; Sweden; WOLF cohort; work ability

This article in PubMed: www.ncbi.nlm.nih.gov/pubmed/31944257 


\title{
Metabolic syndrome - a risk factor for all-cause disability pension: a prospective study based on the Swedish WOLF cohort
}

\author{
by Edvard Lidén, MD, ${ }^{1}$ Berndt Karlsson, MD, PhD, ${ }^{2}$ Kjell Torén, MD, PhD, ${ }^{1}$ Eva Andersson, MD, PhD 1,3
}

\begin{abstract}
Lidén E, Karlsson B, Torén $\mathrm{K}$, Andersson E. Metabolic syndrome - a risk factor for all-cause disability pension: a prospective study based on the Swedish WOLF cohort. Scand J Work Environ Health. 2020;46(4):402-409.
\end{abstract}

\begin{abstract}
Objective The aim was to study the impact of metabolic syndrome on the risk for disability pension among Swedish employees.

Methods A working population-based prospective cohort [Work, Lipids and Fibrinogen (WOLF) cohort, $\mathrm{N}=10$ 803], was linked to national registry records of all-cause disability pension for the period 1992-2013. Occupational health service data included 1992-2009 anthropometric measurements, blood samples, and questionnaires. Metabolic syndrome was defined according to International Diabetes Federation criteria, and risk for any all-cause disability pension was analyzed using Cox proportional hazard regression as hazard ratios (HR) with $95 \%$ confidence intervals (CI) adjusted for age, sex and other covariates.

Results Of the employees, $17.9 \%$ (men $21.5 \%$, women $9.7 \%$ ) met the criteria for metabolic syndrome. The prevalence of all-cause disability pension was $15.2 \%$ in men with metabolic syndrome and $7.5 \%$ in men without metabolic syndrome; for women, the corresponding results were $23.2 \%$ and $12.7 \%$. After adjustment for sociodemographic factors, health behaviors, work-related factors, diabetes, and obesity, the risk for all-cause disability pension among subjects with metabolic syndrome displayed an HR of 1.37 (95\% CI 1.18-1.60). Results were similar for men and women. In a subgroup, further adjustment for chronic diseases resulted in an HR of 1.32 (95\% CI 1.04-1.68)
\end{abstract}

Conclusion This study demonstrates an increased risk for all-cause disability pension, even after adjustment for other risk factors, among Swedish employees with metabolic syndrome compared to those without at baseline.

Key terms abdominal obesity; blood lipid; employee; glucose; hypertension; longitudinal; Sweden; work ability.

In 1998, the World Health Organization (WHO) defined simultaneous occurrence of several cardiovascular risk factors - insulin resistance, dyslipidemia, hypertension, obesity or central obesity (increased waist circumference) - as metabolic syndrome (MetS) $(1,2)$. Several definitions of MetS are valid, each focusing on different metabolic factors in the syndrome. The prevalence of MetS in different European and North American populations is estimated to be $9.4-23.8 \%$ depending on the criteria definition of MetS and the observed population $(3,4)$. Diabetes mellitus type 2 (DM2) and MetS are separate disorders but could both be associated with cardiovascular comorbidity as they share similar metabolic risk factors; there are also indications that MetS in itself could be a precursor of cardiovascular disease and DM2
(5-7). Published data describing work ability and disability pension in diabetic patients in the workforce are numerous (8-11) but there is considerably less, if any, knowledge about the impact of MetS on work ability and the risk for disability pension. Of relevance is a study by Lam \& LeRoith (12) describing the multi-organ effects related to MetS, with insulin resistance playing a key role in the development of MetS and another by Taylor \& MacQueen (13), who in 2007 described the effect on cognitive performance in MetS.

The concept of work disability encompasses several areas of science but its endpoint - disability pension is a statutory or insurance-based construct that depends on identifiable medical diagnoses relating to biological characteristics of an individual. Medically motivated

1 Department of Occupational and Environmental Medicine, Sahlgrenska Academy, University of Gothenburg, Gothenburg, Sweden.

2 Department of Public Health and Clinical Medicine, Umeå University, Umeå, Sweden.

3 Department of Occupational and Environmental Medicine, Sahlgrenska University Hospital, Gothenburg, Sweden.

Correspondence to: Edvard Lidén, MD, Department of Occupational and Environmental Medicine, Sahlgrenska Academy, University of Gothenburg, Gothenburg, Sweden. [E-mail: edvard.liden@amm.gu.se] 
impairments lead to an incapacity of the individual to perform allotted work tasks and maintain gainful full-time employment until retirement age (14). Work ability can be evaluated with prognostic tools such as the Work Ability Index (WAI), but there is a lack of methods for assessing work disability in epidemiological studies (15). The possibility to predict the risk for disability pension has been described in a follow-up study of work-related psychosocial demands (16). Sustained work disability may eventually lead to disability pension, which can be monitored and evaluated using social registry data on disability pension (17).

The Work, Lipids and Fibrinogen (WOLF) cohort is well studied (18). The WOLF surveys are based on questionnaires, clinical examinations, anthropometric measurements, and blood sampling among employees in different branches of work and different parts of Sweden during 1992-2009 and, therefore, provides valuable data for the present study (www.wolfstudy.se).

The aim of this study was to explore the impact of MetS on the probability of disability pension among employees in the Swedish workforce.

\section{Methods}

\section{Design and study population}

We conducted a working population-based prospective cohort study using data collected since 1992 from the WOLF cohort surveys. Study subjects participated in an extensive set of WOLF surveys comprising anthropometric measurements and blood samples at baseline and questionnaires administered on one to three occasions during 1992-1997 and 2000-2003, with a follow-up survey in 2009. The study subjects were 15-64 years of age and were recruited from 36 occupational health service units and employed in 159 different occupations (according to the Nordic Classification of Occupations (19) in approximately 60 companies located in Stockholm county and in the northern Swedish counties of Västernorrland and Jämtland. Workers in the enrolled companies were invited to participate, but subjects on long-term leave from their workplace were not included. Participating workers were employed in transportation, industry, public administration, telecommunications, sales, teaching, construction and finance.

Clinical examination at the occupational health service units included standardized measurement of blood pressure (BP) and measurements of length, weight, and waist and hip circumference. Sampling of fasting blood glucose (FPG) and blood lipids followed standardized procedures and the blood samples were analyzed at an accredited laboratory. The WOLF survey questionnaires addressed work and health conditions, socio-demographic status, and job strain and other psychosocial factors. The questionnaires also included questions on tobacco and alcohol use, exercise habits, and cardiovascular risk factors.

For 10803 study subjects derived from the WOLF cohort, complete information on parameters regarding MetS was available. In the northern Swedish counties, 2013 subjects completed a second clinical investigation. All participants in earlier WOLF surveys were invited to respond to the 2009 follow-up survey, 6352 subjects answered and thus formed a sub-group. The final 2009 survey also included questions regarding specific chronic diseases.

\section{Definitions}

Disability pension. We chose to use any all-cause disability pension (full- or part-time) as a proxy for work disability. The WOLF cohort data were matched with de-identified data from an official registry, the Longitudinal Integrations Database for Health Insurance and Labor Market Studies (LISA) registry, published by Statistics Sweden (SCB). The LISA register is updated yearly and comprises aggregated socio-economic and demographic data, derived from different registers, on all citizens aged $\geq 16$ years living in Sweden (www.scb. se). The LISA database is enabled by the use of unique personal identification numbers (PIN) (20). In this study, the matching LISA data cover the years 1990-2013, and the subjects were followed regarding all-cause disability pension from their first year in the study until the last year of the follow-up. Statistics Sweden carried out the merging of data for all subjects in the WOLF cohort with corresponding data from the LISA database. The merged data for the study period 1990-2013 were then anonymized (ie, the PIN were removed) and sent back for further analysis.

Metabolic syndrome. Of the different definitions of MetS, we preferred using the definition given in 2005 by the International Diabetes Federation (IDF) (www.idf.org) (21), for analysis of the WOLF survey data. The IDF criteria for the MetS require the mandatory presence of central obesity (a circumferential waist measurement of $\geq 94 \mathrm{~cm}$ for men and $\geq 80 \mathrm{~cm}$ for women) and the presence of $\geq 2$ of 4 of the following criteria: (i) raised FPG $\geq 100 \mathrm{mg} / \mathrm{dL}$ (5.6 mmol/L) or diagnosed diabetes; (ii) raised $\mathrm{BP}$, with systolic $\mathrm{BP}>130$ or diastolic $\mathrm{BP}>85$ $\mathrm{mmHg}$, or treatment for diagnosed hypertension; (iii) raised triglycerides $\geq 150 \mathrm{mg} / \mathrm{dL}(1.7 \mathrm{mmol} / \mathrm{L})$ or pharmaceutical treatment for blood lipids; and (iv) reduced level of high-density lipoprotein cholesterol (HDL-C), of $<40 \mathrm{mg} / \mathrm{dL}(1.0 \mathrm{mmol} / \mathrm{L})$ in males and $<50 \mathrm{mg} / \mathrm{dL}$ $(1.3 \mathrm{mmol} / \mathrm{L})$ in females, or pharmaceutical treatment 
for blood lipids. Information on use of pharmaceutical treatment and diabetes diagnosis was derived from the questionnaires.

The study population was divided into two groups, those with MetS at baseline or at the second clinical investigation (MetS group) and those without metabolic syndrome (non-MetS group). If a study subject met the MetS criteria at the second medical investigation, this occasion constituted baseline in the further analyses.

Socio-demographic factors. Region was classified according to employment location as $0=$ Stockholm county, and $1=$ the counties of Västernorrland and Jämtland. Job level was derived from the LISA registry, and 10-13 occupationally based socio-economic groups (the division of groups was changed by the SCB during the follow-up time) were categorized into three levels. In the final analyses, levels 2 and 3 were combined (as their results were similar) and compared with the highest job level (level 1). Classification of education was done based on the baseline questionnaire, where one item covered nine types of school as well as university education. Educational level was divided into low (6-9 years) and high (university or similar), both of which were compared with medium-length education. Civil status was derived from the baseline questionnaire, with four response alternatives (married or cohabiting/unmarried/ divorced/widowed) classified as $0=$ married or cohabiting, while $1=$ single.

Health behaviors. Smoking habits were derived from items in the baseline questionnaire and categorized as ever-smoking or not. Physical exercise was assessed from the baseline questionnaire item "How often do you exercise?" The item had four response alternatives (never/rarely/sometimes/regularly), with "never" and "rarely" classified as low exercise level and "regularly" as high exercise level. "Sometimes" was used as the reference value.

Work-related factors. Level of control was classified according to the demand-control model (22) with five items on demand and six on decision latitude (control) derived from the baseline questionnaire. The items had four response alternatives (yes, often/yes, sometimes/ no, rarely/no, never) scoring 1-4 points. The sum was calculated, and the median was used to classify high demand and low control, respectively, as 1. High strain (defined as having both high demand and low control) was also tested but it was low control that demonstrated the strongest association with disability pension and that was therefore used in the analyses. Physical workload at work was classified from the baseline questionnaire, the subjects were asked to assess how physically demanding their work was on a scale of $0=$ very, very light to
$14=$ very, very strenuous. We classified $0-3$ as low and 9-14 as high physical workload and compared them with moderate physical workload of 4-8.

Metabolic syndrome-related factors. Diabetes was derived from the baseline questionnaire question "Do you have diabetes?" (yes/no). Body mass index (BMI) was calculated from baseline measurements of weight and length. A BMI $\geq 30$ was defined as obesity (23).

Chronic diseases. From the questionnaire administered at follow-up in 2009, the item "Do you have or have you had any physician-diagnosed diseases or disorders during the last 5 years?" - with specific disease alternatives and three answer alternatives for each disease/disorder (no, not at all/not now, but during the last 5 years / yes, now) - was used to classify "no, not at all" as 0 and the other two responses as 1 . These diseases were included in the analysis as they could affect work ability: rheumatologic diseases, musculoskeletal disorders, cardiovascular diseases, psychiatric disease, and asthma/ obstructive lung disease.

\section{Statistical analysis}

Frequencies of baseline characteristics, such as MetS criteria and potential risk factors (covariates) for all-cause disability pension used in the analyses, were calculated for all subjects, and for men and women in the MetS and non-MetS group, respectively. For continuous variables, mean values with standard deviations (SD) were calculated. Time at risk (in person-years) was calculated from entry into the study between 1992-2003 (94\% of the subjects were included at the end of 1997) until the end of follow-up. End of follow up was the first occurring event of: (i) disability pension, (ii) death, (iii) unavailable in the LISA registry (not registered as a resident in Sweden at the last day of the year, $2.5 \%$ ), (iv) retirement at age 65 or before, or (v) the end of the study period in 2013. Incidence rates per 1000 person-years, with $95 \%$ confidence intervals (CI), were calculated for first occurrence of all-cause disability pension during time at risk for men and women in the MetS and non-MetS groups, respectively. The risk for all-cause disability pension due to MetS was analyzed using Cox proportional hazard regression in a base model (model 1) adjusting for both age (in years) at study entry and sex, yielding hazard ratios (HR) with 95\% CI. Further, three models were analyzed adjusting also for three different sets of covariates: model 2 - base factors and socio-demographic factors (region, job level, education level - low and high compared with medium-length education - and civil status), model 3 - base factors and health behaviors (ever-smoking, physical exercise - low and high exercise level, compared with exercising "sometimes") and model 
4 - base factors and work-related factors (low control in the demand-control model, physical workload at work - low and high workload compared with moderate physical workload). In model 5 (non-MetS-related factors), all three sets of covariates were analyzed together with the base model. In model 6 , the base model was analyzed together with the MetS-related factors diabetes and obesity. The final model, model 7, adjusted for all above-mentioned factors.

All covariates were significant when analyzed in models $2-4$, and most but not all were significant in the final adjusted model. All covariates but one (region) were separately significant in the base model.

Risk consumption of alcohol, estimated from the baseline questionnaire, was tested with the base model but HR was not increased and it did not change the estimate of MetS and therefore it was omitted. The item "ever shift work" (from the baseline questionnaire) tested with the base model was significantly increased but when tested with the set of work-related factors gave a P-value of 0.44 and was therefore omitted. The seven models were also performed for men and women separately. The same calculations were done for the subgroup ( $\mathrm{N}=6352)$.

The SAS program version 9.4 (SAS Institute, Cary, NC, USA) was used for the analyses. For Cox regres- sions, the PHREG procedure in SAS was applied, and this was also used when proportionality of hazards was tested using log-log survival functions.

The Review board of the Regional Ethics Committee at the University of Gothenburg approved the study (082-15, 26 March 2015).

\section{Results}

The entire study population consisted of 10803 employed subjects $(69.5 \%$ men, $30.5 \%$ women $)$. Of these, $17.9 \%$ (21.5\% of men, $9.7 \%$ of women) met the IDF criteria for MetS. Baseline characteristics and covariates of the study subjects are presented in table 1. Of the study population $41.9 \%$ had central obesity at the start of study, and of these $25.5 \%$ were obese (BMI $\geq 30$ ). Of those with MetS, $65.4 \%$ were not obese $(\mathrm{BMI} \geq 30)$. In the non-MetS group, $27.8 \%$ of men and $32.1 \%$ of women had a waist circumference exceeding the IDF criteria but did not fulfill the other criteria required for definition of MetS. Elevated FPG levels or treatment for diabetes were evident in $5.8 \%$ of subjects in the non-MetS group, but only $0.8 \%$ of them had a diabetes diagnosis.

Table 1. Baseline characteristics and covariates, by gender, of subjects in the non-metabolic syndrome (non-MetS) and metabolic syndrome (MetS) groups. [IDF=International Diabetes Federation; HDL-C=high-density lipoprotein cholesterol; BMI=body mass index; T=treatment].

\begin{tabular}{|c|c|c|c|c|c|c|c|c|}
\hline & \multicolumn{2}{|c|}{ Men } & \multicolumn{2}{|c|}{ Women } & \multicolumn{2}{|c|}{ All } & \multirow[b]{2}{*}{$\begin{array}{c}\text { All } \\
(\mathrm{N}=10803)\end{array}$} & \multirow[b]{2}{*}{$\mathrm{N}$} \\
\hline & $\begin{array}{l}\text { Non-MetS } \\
(\mathrm{N}=5893)\end{array}$ & $\begin{array}{c}\text { MetS } \\
(\mathrm{N}=1614)\end{array}$ & $\begin{array}{l}\text { Non-MetS } \\
(\mathrm{N}=2977)\end{array}$ & $\begin{array}{c}\text { MetS } \\
(\mathrm{N}=319)\end{array}$ & $\begin{array}{l}\text { Non-MetS } \\
(\mathrm{N}=8870)\end{array}$ & $\begin{array}{c}\text { MetS } \\
(\mathrm{N}=1933)\end{array}$ & & \\
\hline & $\%$ & $\%$ & $\%$ & $\%$ & $\%$ & $\%$ & $\%$ & \\
\hline \multicolumn{9}{|l|}{ IDF criteria for metabolic syndrome } \\
\hline $\begin{array}{l}\text { Central obesity, men } \geq 94 \mathrm{~cm} \text {, } \\
\text { women } \geq 80 \mathrm{~cm}\end{array}$ & 27.8 & 100 & 32.1 & 100 & 29.3 & 100 & 41.9 & 10803 \\
\hline Triglycerides $\geq 1.7 \mathrm{mmol} / \mathrm{L}$ or $\mathrm{T}$ & 18.4 & 82.3 & 3.4 & 60.5 & 13.3 & 78.7 & 25.0 & 10803 \\
\hline $\begin{array}{l}\mathrm{HDL}-\mathrm{C} \text {, men, } \leq 1.0 \mathrm{mmol} / \mathrm{L} \text {, women, } \\
\leq 1.3 \mathrm{mmol} / \mathrm{L} \text { or } \mathrm{T}\end{array}$ & 8.7 & 42.6 & 10.8 & 66.1 & 9.4 & 46.5 & 16.0 & 10803 \\
\hline $\begin{array}{l}\text { Hypertension, systolic } \geq 130 \\
\mathrm{mmHg} \text {, diastolic } \geq 85 \mathrm{mmHg} \text { or } \mathrm{T}\end{array}$ & 31.3 & 78.3 & 22.2 & 77.4 & 28.3 & 78.1 & 37.2 & 10803 \\
\hline $\begin{array}{l}\text { Fasting glucose, } \geq 5.6 \mathrm{mmol} / \mathrm{L} \text { or } \\
\text { diagnosed diabetes }\end{array}$ & 7.3 & 39.9 & 2.8 & 33.9 & 5.8 & 38.9 & 11.7 & 10803 \\
\hline \multicolumn{9}{|l|}{ Covariates } \\
\hline Diabetes diagnosis & 0.9 & 4.8 & 0.5 & 6.6 & 0.8 & 5.1 & 1.6 & 10747 \\
\hline Obesity $(\mathrm{BMI} \geq 30)$ & 5.3 & 34.2 & 6.3 & 37.0 & 5.6 & 34.6 & 10.8 & 10800 \\
\hline $\begin{array}{l}\text { Counties of Västernorrland and } \\
\text { Jämtland, Sweden }\end{array}$ & 53.7 & 69.3 & 24.1 & 49.2 & 43.7 & 66.0 & 47.7 & 10803 \\
\hline Job level: low and medium & 62.2 & 66.0 & 60.1 & 74.8 & 61.5 & 67.5 & 62.6 & 10713 \\
\hline Education level: Iow (<10 years) & 16.8 & 26.5 & 12.7 & 21.6 & 15.4 & 25.7 & 17.3 & 10803 \\
\hline $\begin{array}{l}\text { Education level: high (university } \\
\text { level or similar) }\end{array}$ & 24.6 & 14.7 & 37.3 & 21.9 & 28.9 & 15.9 & 26.5 & 10803 \\
\hline Civil status: single & 25.2 & 23.4 & 28.4 & 21.6 & 26.2 & 23.1 & 25.7 & 10777 \\
\hline Smoking habits: ever-smoking & 47.4 & 62.2 & 53.2 & 59.6 & 49.4 & 61.8 & 51.6 & 10535 \\
\hline $\begin{array}{l}\text { Leisure-time physical activity: } \\
\text { rarely or never }\end{array}$ & 23.8 & 37.8 & 19.9 & 30.8 & 22.5 & 36.7 & 25.0 & 10769 \\
\hline $\begin{array}{l}\text { Leisure-time physical activity: } \\
\text { regularly }\end{array}$ & 36.6 & 20.9 & 46.6 & 29.9 & 39.9 & 22.3 & 36.8 & 10769 \\
\hline $\begin{array}{l}\text { Low job decision latitude according } \\
\text { to the Karasek model }\end{array}$ & 54.3 & 59.3 & 56.9 & 65.5 & 55.2 & 60.3 & 56.1 & 9974 \\
\hline Physical workload at work: low & 35.6 & 32.4 & 50.4 & 43.6 & 40.5 & 34.2 & 39.1 & 10738 \\
\hline Physical workload at work: high & 14.1 & 11.0 & 9.7 & 12.5 & 12.6 & 11.3 & 12.4 & 10738 \\
\hline
\end{tabular}


The results from baseline measurements and blood samples for study subjects with or without MetS are presented in table 2. Age at inclusion was about 6 years lower in the non-MetS group $(\mathrm{P}<0.05)$. Measurements and blood samples displayed elevated levels of triglycerides, FPG and systolic and diastolic BP, and lower levels of HDL-C in the MetS group compared with the non-MetS group, as expected.

Table 3 illustrates the proportion of subjects receiving all-cause disability pension as well as the mean age at disability pension and the incidence rate of allcause disability pension. Total person-years at risk were 149 938, with a mean of 14.4 (SD 5.3) years for the nonMetS group and 11.4 (SD 5.5) years for the MetS group (data not shown). All-cause disability pension occurred in $7.5 \%$ of men in the non-MetS group compared with $15.2 \%$ in the MetS group; for women, the corresponding figures were $12.7 \%$ and $23.2 \%$, respectively. The incidence rate of all-cause disability pension for subjects in the non-MetS group was 6.4 per 1000 person-years and 14.5 for subjects with MetS. Mean age at all-cause disability pension was similar between men and women in the MetS group but not in the non-MetS group. The mean age at all-cause disability pension for all subjects in the study was 55.4 years of age (SD 7.5).

Table 4 displays the risk of all-cause disability pension among subjects with MetS, with adjustment for potential explanatory and mediating factors at baseline. After adjustment for all covariates the final HR for allcause disability pension in the MetS group subjects was 1.37 (95\% CI 1.18-1.60) compared with the non-MetS group. Socio-demographic factors, health behaviors and work-related factors all influenced the risk for all-cause disability pension. However, the increased risk for allcause disability pension remained elevated in the MetS group when adjusting for these factors. The final HR for women will be 1.34 (95\% CI 1.01-1.79) if we exclude the non-significant factors $(\mathrm{P}>0.20)$ in model 7 (data not shown).

With adjustment for diabetes and obesity in the base model, the HR for all-cause disability pension in the MetS group was 1.41 (95\% CI 1.22-1.63). The risk for all-cause disability pension when having diabetes was 2.10 (95\% CI 1.56-2.82) in this model (data not shown). The results were similar for men and women in all combinations of chosen covariates in the specified models.

The subgroup answering the follow-up questionnaire in 2009 had similar baseline characteristics and covariates as the whole study population (data not shown). In the base model for the subgroup the risk for all-cause disability pension was 1.84 (95\% CI $1.53-2.21)$ in the MetS group. After adjusting for reported chronic diseases, HR was 1.52 (95\% CI 1.23-1.89) and after adjusting for chronic diseases and all other covariates,

Table 2. Baseline measurements and age, by gender, of subjects in the non-metabolic syndrome (non-MetS) and metabolic syndrome (MetS) groups. [SD=standard deviation; HDL-C=high-density lipoprotein cholesterol]

\begin{tabular}{|c|c|c|c|c|c|c|c|c|c|c|c|c|c|c|}
\hline & \multicolumn{4}{|c|}{ Men } & \multicolumn{4}{|c|}{ Women } & \multicolumn{4}{|c|}{ All } & \multirow{2}{*}{\multicolumn{2}{|c|}{$\begin{array}{c}\text { Total } \\
\text { All workers } \\
(\mathrm{N}=10803)\end{array}$}} \\
\hline & \multicolumn{2}{|c|}{$\begin{array}{l}\text { Non-MetS } \\
(\mathrm{N}=5893)\end{array}$} & \multicolumn{2}{|c|}{$\begin{array}{c}\text { MetS } \\
(\mathrm{N}=1614)\end{array}$} & \multicolumn{2}{|c|}{$\begin{array}{l}\text { Non-MetS } \\
(\mathrm{N}=2977)\end{array}$} & \multicolumn{2}{|c|}{$\begin{array}{c}\text { MetS } \\
(N=319)\end{array}$} & \multicolumn{2}{|c|}{$\begin{array}{l}\text { Non-MetS } \\
(\mathrm{N}=8870)\end{array}$} & \multicolumn{2}{|c|}{$\begin{array}{c}\text { MetS } \\
(N=1933)\end{array}$} & & \\
\hline & Mean & SD & Mean & SD & Mean & SD & Mean & SD & Mean & SD & Mean & SD & Mean & SD \\
\hline Age at inclusion in the study, years & 41.4 & 10.9 & $46.9^{a}$ & 9.4 & 41.4 & 10.7 & $48.6^{a}$ & 8.9 & 41.4 & 10.8 & $47.1^{\mathrm{a}}$ & 9.3 & 42.4 & 10.8 \\
\hline Central obesity, waist circumference, $\mathrm{cm}$ & 89.7 & 8.8 & 103.3 & 7.9 & 76.9 & 9.2 & 93.7 & 10.2 & 85.4 & 10.8 & 101.7 & 9.1 & 88.3 & 12.2 \\
\hline Triglycerides, $\mathrm{mmol} / \mathrm{L}$ & 1.3 & 0.8 & 2.5 & 1.5 & 0.9 & 0.4 & 1.9 & 1.0 & 1.1 & 0.7 & 2.4 & 1.4 & 1.4 & 1.0 \\
\hline $\mathrm{HDL}-\mathrm{C}, \mathrm{mmol} / \mathrm{L}$ & 1.4 & 0.3 & 1.1 & 0.3 & 1.7 & 0.4 & 1.3 & 0.3 & 1.5 & 0.4 & 1.2 & 0.3 & 1.4 & 0.4 \\
\hline Blood pressure, systolic, mmHg & 123 & 13.9 & 136 & 16.3 & 118 & 14.4 & 136 & 17.7 & 121 & 14.3 & 136 & 16.6 & 124 & 15.7 \\
\hline Blood pressure, diastolic, $\mathrm{mmHg}$ & 74 & 9.8 & 82 & 10.6 & 72 & 9.5 & 80 & 10.0 & 73 & 9.8 & 82 & 10.5 & 75 & 10.4 \\
\hline Fasting plasma glucose (FPG), $\mathrm{mmol} / \mathrm{L}$ & 5.2 & 0.8 & 6.0 & 1.6 & 4.9 & 0.7 & 5.9 & 1.8 & 5.1 & 0.8 & 5.9 & 1.6 & 5.3 & 1.1 \\
\hline
\end{tabular}

Table 3. Incidence of all-cause disability pension during follow-up among subjects in the non-metabolic syndrome (non-MetS) and metabolic syndrome (MetS) groups, incidence rate per 1000 person-years (IR/1000 py), with 95\% confidence intervals (CI). [SD=standard deviation].

\begin{tabular}{|c|c|c|c|c|c|c|c|c|}
\hline & \multirow{2}{*}{$\frac{\text { Subjects }}{\mathrm{N}}$} & \multirow{2}{*}{$\begin{array}{c}\text { Time at risk } \\
\text { Person-years }\end{array}$} & \multicolumn{2}{|c|}{ All-cause disability pension } & \multicolumn{2}{|c|}{ Age at disability pension, years } & \multicolumn{2}{|c|}{ Incidence rate } \\
\hline & & & $\mathrm{N}$ & $\%$ & Mean & SD & IR/1000 py & $95 \% \mathrm{Cl}$ \\
\hline All subjects & 10803 & 149938 & 1137 & 10.5 & 55.4 & 7.5 & 7.6 & $7.1-8.0$ \\
\hline Non-MetS & 8870 & 127836 & 817 & 9.2 & 55.0 & 7.8 & 6.4 & $6.0-6.8$ \\
\hline MetS & 1933 & 22102 & 320 & 16.6 & 56.4 & 6.3 & 14.5 & $12.9-16.2$ \\
\hline Non-MetS men & 5893 & 83940 & 440 & 7.5 & 55.9 & 7.3 & 5.2 & $4.8-5.8$ \\
\hline MetS men & 1614 & 18733 & 246 & 15.2 & 56.5 & 6.1 & 13.1 & $11.5-14.8$ \\
\hline Non-MetS women & 2977 & 43896 & 377 & 12.7 & 53.9 & 8.3 & 8.6 & $7.7-9.5$ \\
\hline MetS women & 319 & 3369 & 74 & 23.2 & 56.0 & 6.9 & 22.0 & $17.2-27.6$ \\
\hline
\end{tabular}


Table 4. Risk of all-cause disability pension among subjects with metabolic syndrome (MetS), adjusted for potential explanatory and mediating factors at baseline. Risks are given as hazard ratios (HR) with 95\% confidence intervals (CI).

\begin{tabular}{|c|c|c|c|c|c|c|}
\hline \multirow[t]{2}{*}{ Model } & \multicolumn{2}{|c|}{ Men $(N=7507)$} & \multicolumn{2}{|c|}{ Women (N=3296) } & \multicolumn{2}{|c|}{ Total (N=10 803) } \\
\hline & $\mathrm{HR}$ & $95 \% \mathrm{Cl}$ & $\mathrm{HR}$ & $95 \% \mathrm{Cl}$ & $\mathrm{HR}$ & $95 \% \mathrm{Cl}$ \\
\hline Age (and sex)-adjusted base model a & 1.66 & $1.41-1.94$ & 1.58 & $1.23-2.04$ & 1.63 & $1.43-1.87$ \\
\hline Adjusted for socio-demographic factors ${ }^{b}$ & 1.58 & $1.35-1.85$ & 1.48 & $1.14-1.91$ & 1.55 & $1.35-1.77$ \\
\hline Adjusted for health behaviors ${ }^{c}$ & 1.55 & $1.32-1.83$ & 1.53 & $1.18-1.98$ & 1.55 & $1.36-1.78$ \\
\hline Adjusted for work-related factors ${ }^{d}$ & 1.61 & $1.37-1.90$ & 1.56 & $1.20-2.04$ & 1.60 & $1.40-1.84$ \\
\hline Adjusted for non-MetS-related factors ${ }^{\mathrm{e}}$ & 1.55 & $1.31-1.83$ & 1.51 & $1.15-1.97$ & 1.54 & $1.34-1.78$ \\
\hline Adjusted for diabetes and obesity ${ }^{f}$ & 1.44 & $1.21-1.71$ & 1.35 & $1.02-1.78$ & 1.41 & $1.22-1.63$ \\
\hline Adjusted for all above factors ${ }^{g}$ & 1.40 & $1.17-1.69$ & 1.31 & $0.98-1.76$ & 1.37 & $1.18-1.60$ \\
\hline
\end{tabular}

a Model 1: age (sex) at inclusion in the study.

${ }^{b}$ Model 2: age (sex), region, job level, low education, university education, civil status (all factors significant).

${ }^{c}$ Model 3: age (sex), ever-smoking, low exercise, regular exercise (all factors significant).

a Model 4: age (sex), low control (according to the demand-control model), low physical workload, high physical workload at work (all factors significant).

e Model 5: age (sex), region, job level, low education, university studies, civil status, ever-smoking, low exercise, regular exercise, low control at work (according to the demand-control model), low physical workload at work, high physical workload at work (most factors significant).

${ }^{f}$ Model 6: age (sex), diabetes and obesity (all factors significant).

${ }^{9}$ Model 7: age (sex), region, low education, university studies, civil status, ever-smoking, low exercise, regular exercise, low control at work (according to the demandcontrol model), low physical workload at work, high physical workload at work, diabetes and obesity (most factors significant).

HR was 1.32 (95\% CI 1.04-1.68). For women in the MetS group, the risk for all-cause disability pension was non-significant when adjusting for reported chronic diseases in the base model, HR 1.21 (95\% CI 0.81-1.81). Among men the corresponding analysis yielded an HR of 1.69 (95\% CI 1.30-2.19).

\section{Discussion}

The main finding in this working life prospective study is that Swedish employees with MetS had a considerably elevated risk of all-cause disability pension compared with employees without MetS. The risk for all-cause disability pension remained elevated after adjustment for other covariates such as age at inclusion in the study, sex, socio-demographic factors, health behaviors, workrelated factors including the demand-control model, and the MetS-related factors diabetes and obesity. To our knowledge, this is the first study on this topic.

The presence of MetS or non-MetS was based on an internationally recognized definition of MetS, the IDF criteria, which is clinically useful (21). Measurements of waist circumference, BMI, BP, blood samples of FPG and blood lipids are easily accessible in everyday medical practice. The IDF criteria also allow comparison with the results from other studies using the same or comparable MetS criteria. This study found similar results, concerning MetS, as reported in previous studies in which the prevalence was estimated to be about $10-20 \%$, depending on the criteria definition for MetS, as well as the population and the subjects' age (3).

Our study is based on a long-term follow-up of a representative cohort of employed men and women of normal working age, recruited from a variety of occupations at workplaces located in three counties in Sweden. Data collection in the WOLF surveys was based on self-administered questionnaires and closely supervised by local occupational health service personnel who also performed standardized measurements and blood sampling. The assessment of MetS was based on at least one health examination carried out in the WOLF cohort at each subject's entrance year into the study. The health examination included the necessary measurements and blood samples to confirm or reject the MetS diagnosis. The assessment of self-reported chronic disease or conditions of importance was first established in the final survey questionnaire in 2009 . The quality of data in the LISA database depends on the registries that supply data to the database; and the linkage between these registers is by use of the individual PIN code as a common denominator (20).

Since the 2009 WOLF survey did not comprise measurements and blood sampling, the true prevalence of MetS in the cohort at the end of the study period is not known even though this study shows that one-third of subjects in the non-MetS group met the prerequisite for MetS, increased waist circumference, but did not fulfill the other MetS criteria at baseline.

The main focus in this study was working employees; those on long-term leave from their workplace were excluded. The size of the total workforce is therefore not known, which may have led to a possible underestimation of the risk of all-cause disability pension.

The complex mechanisms in MetS leading to reduced work ability and, eventually, the loss of work ability are not fully understood. Insulin resistance, visceral adiposity and atherogenic dyslipidemia are known interrelated features sharing common mediators and pathophysi- 
ological mechanisms (2). We therefore wanted to adjust for diabetes and obesity in our analyses, but that did not account for the risk for disability pension among subjects with MetS.

Another aspect of work ability is the cognitive requirements in modern working life. In a complex working life, cognitive demands are crucial for productivity and could therefore be affected by the complex neuroanatomical and neuroendocrine changes inherent in MetS, as described by Taylor \& MacQueen (13).

The chain of action explaining why MetS leads to an elevated risk of disability pension is to some extent understood concerning risk factors and mechanisms, but the complex underlying causes of loss of work ability are not known.

\section{Implications}

In this study, we found an overall elevated risk of allcause disability pension among study subjects with MetS. The implications of this new knowledge are that it could, through screening of groups with at least one risk factor, contribute to an awareness of the importance of early medical recognition of MetS, enabling necessary lifestyle changes, medical treatment and adequate intervention at the workplace in order to maintain work ability throughout the working life.

Contrary to MetS, DM2 is a well-known identifiable condition, which is often recognized early and monitored and medically treated, and whose impact on work ability and risk for disability pension is described in numerous studies (8-10). In this study, the number of subjects with MetS by far exceeded the number of subjects with diagnosed DM2; however, compared with DM2, MetS is much less of a diagnosed and medically treated entity. This is also understood by the fact that MetS is not recognized as a definable unique International Classification of Diseases, $10^{\text {th }}$ revision (ICD-10), diagnostic code; although the definition "metabolic syndrome" was established by WHO already in $1998(1,24)$. Today the risk factors related to metabolic disorders - obesity, abdominal obesity, blood lipid disturbances, hypertension, and insulin resistance with diabetic and non-diabetic hyper glycaemia - are often separately diagnosed and medically treated. A patient with hypertension or lipid disturbances is not routinely checked for waist circumference, and vice versa, but measurement of waist circumference is mandatory in establishing the entity of MetS, using the IDF criteria. These shortcomings complicate systematic preventive actions. The lack of a recognized diagnostic entity with an ICD-10 diagnostic code also implies that subjects with unidentified MetS are at risk of being without proper lifestyle interventions and medical care for the combined risk burden of the syndrome and also of work disability, and may eventually end their working life at an earlier stage, with a disability pension, as illustrated in this study.

\section{Concluding remarks}

Many factors are involved in the risk of all-cause disability pension but the presence of MetS was an independent and significant risk factor in this study.

\section{Acknowledgements}

The authors declare no conflicts of interest. The authors would like to thank the steering committee of WOLF and Maria Nordin, a member of the committee, who kindly provided data from the WOLF cohort surveys. The study was funded by the agreement on medical training and research between the Swedish government and the regions (ALF).

\section{References}

1. Alberti KG, Zimmet PZ. Definition, diagnosis and classification of diabetes mellitus and its complications. Part 1: diagnosis and classification of diabetes mellitus provisional report of a WHO consultation. Diabet Med 1998 Jul;15(7):539-53. https://doi.org/10.1002/(SICI)10969136(199807)15:7<539::AID-DIA668>3.0.CO;2-S.

2. Huang PL. A comprehensive definition for metabolic syndrome. Dis Model Mech 2009 May-Jun;2(5-6):231-7. https://doi.org/10.1242/dmm.001180.

3. Scuteri A, Laurent S, Cucca F, Cockcroft J, Cunha PG, Mañas LR et al.; Metabolic Syndrome and Arteries Research (MARE) Consortium. Metabolic syndrome across Europe: different clusters of risk factors. Eur J Prev Cardiol 2015 Apr;22(4):486-91. https://doi. org/10.1177/2047487314525529.

4. O'Neill S, O'Driscoll L. Metabolic syndrome: a closer look at the growing epidemic and its associated pathologies. Obes Rev 2015 Jan;16(1):1-12. https://doi.org/10.1111/obr.12229.

5. Wilson PW, D'Agostino RB, Parise H, Sullivan L, Meigs JB. Metabolic syndrome as a precursor of cardiovascular disease and type 2 diabetes mellitus. Circulation 2005 Nov;112(20):3066-72. https://doi. org/10.1161/CIRCULATIONAHA.105.539528.

6. Chen K, Lindsey JB, Khera A, De Lemos JA, Ayers $\mathrm{CR}$, Goyal A et al. Independent associations between metabolic syndrome, diabetes mellitus and atherosclerosis: observations from the Dallas Heart Study. Diab Vasc Dis Res 2008 Jun;5(2):96-101. https://doi.org/10.3132/ dvdr.2008.016.

7. Jeppesen J, Hansen TW, Rasmussen S, Ibsen H, 
Torp-Pedersen C, Madsbad S. Insulin resistance, the metabolic syndrome, and risk of incident cardiovascular disease: a population-based study. J Am Coll Cardiol 2007 May;49(21):2112-9. https://doi.org/10.1016/j. jacc.2007.01.088.

8. Kivimäki M, Vahtera J, Pentti J, Virtanen M, Elovainio $\mathrm{M}$, Hemingway $\mathrm{H}$. Increased sickness absence in diabetic employees: what is the role of co-morbid conditions? Diabet Med 2007 Sep;24(9):1043-8. https://doi.org/10.1111/j.14645491.2007.02216.x.

9. Detaille SI, Heerkens YF, Engels JA, van der Gulden JW, van Dijk FJ. Common prognostic factors of work disability among employees with a chronic somatic disease: a systematic review of cohort studies. Scand J Work Environ Health 2009 Jul;35(4):261-81. https://doi.org/10.5271/ sjweh.1337.

10. Herquelot E, Guéguen A, Bonenfant S, Dray-Spira R. Impact of diabetes on work cessation: data from the GAZEL cohort study. Diabetes Care 2011 Jun;34(6):1344-9. https:// doi.org/10.2337/dc10-2225.

11. Ervasti J, Virtanen M, Pentti J, Lallukka T, Tinghög P, Kjeldgard L et al. Work disability before and after diabetes diagnosis: a nationwide population-based register study in Sweden. Am J Public Health 2015 Jun;105(6):e22-9. https:/ doi.org/10.2105/AJPH.2015.302646.

12. Lam DW, LeRoith D. Metabolic syndrome. MDText.com Inc. 2015.

13. Taylor VH, MacQueen GM. Cognitive dysfunction associated with metabolic syndrome. Obes Rev 2007 Sep;8(5):409-18. https://doi.org/10.1111/j.1467789X.2007.00401.x.

14. Stattin M. Retirement on grounds of ill health. Occup Environ Med 2005 Feb;62(2):135-40. https://doi.org/10.1136/ oem.2004.015669.

15. Ilmarinen J, Tuomi K, Klockars M. Changes in the work ability of active employees over an 11-year period. Scand J Work Environ Health 1997;23 suppl 1:49-57.

16. Canivet C, Choi B, Karasek R, Moghaddassi M, StalandNyman C, Östergren PO. Can high psychological job demands, low decision latitude, and high job strain predict disability pensions? A 12-year follow-up of middle-aged Swedish workers. Int Arch Occup Environ Health 2013 Apr;86(3):307-19. https://doi.org/10.1007/s00420-0120766-4.
17. Statistics Sweden. Longitudinal Integrations Database for Health Insurance and Labor Market Studies Örebro: Statistics Sweden, SCB. 2016.

18. Karlsson BH, Knutsson AK, Lindahl BO, Alfredsson LS. Metabolic disturbances in male workers with rotating three-shift work. Results of the WOLF study. Int Arch Occup Environ Health 2003 Jul;76(6):424-30. https://doi. org/10.1007/s00420-003-0440-y.

19. Nordic classification of occupations. [Nordisk yrkesklassificering]. Svensk grundstandard. Stockholm. Liber förlag. 1983.

20. Ludvigsson JF, Otterblad-Olausson P, Pettersson BU, Ekbom A. The Swedish personal identity number: possibilities and pitfalls in healthcare and medical research. Eur J Epidemiol 2009;24(11):659-67. https://doi. org/10.1007/s10654-009-9350-y.

21. International Diabetes Federation Task Force on Epidemiology and Prevention. The IDF consensus worldwide definition of the METABOLIC SYNDROME. International Diabetes Federation. 2006.

22. Karasek RA, Theorell T. Healthy work - stress productivity and the construction of working lift. New York: Basic Press. 1990.

23. World Health Organization. WHO. Body Mass Index BMI. http://www.euro.who.int/en/health-topics/diseaseprevention/nutrition/a-healthy-lifestyle/body-mass-indexbmi.

24. Alberti KG, Eckel RH, Grundy SM, Zimmet PZ, Cleeman JI, Donato KA et al.; International Diabetes Federation Task Force on Epidemiology and Prevention; Hational Heart, Lung, and Blood Institute; American Heart Association; World Heart Federation; International Atherosclerosis Society; International Association for the Study of Obesity. Harmonizing the metabolic syndrome: a joint interim statement of the International Diabetes Federation Task Force on Epidemiology and Prevention; National Heart, Lung, and Blood Institute; American Heart Association; World Heart Federation; International Atherosclerosis Society; and International Association for the Study of Obesity. Circulation 2009 Oct;120(16):1640-5. https://doi. org/10.1161/CIRCULATIONAHA.109.192644.

Received for publication: 5 June 2019 